\title{
VARICOSE VEINS STAGE DOWN BEFORE SURGERY
}

\author{
By
Mohammed Ahmed Ahmed Abd El-Tawab, Ishak Abd El-Aaal Abd El- Alay and Mohamed Yahia Zakaria* \\ Departments of General Surgery and *Vascular Surgery, Faculty of Medicine, Al-Azhar \\ University \\ Corresponding Author: Mohammed Ahmed Ahmed Abd El-Tawab, \\ E-mail: dr.m.ahmed.abdeltawab@gmail.com
}

\begin{abstract}
Background: For many people, varicose veins and spider veins are simply a cosmetic concern. For other people, varicose veins can cause aching pain and discomfort. Sometimes varicose veins lead to more-serious problems.

Objective: To evaluate the effect of staging down of the lower limb varicose veins by injection sclerotherapy before surgical treatment in comparison with the standard procedure.

Patients and Methods: Included 40 patients, aged 25-42 years (Range), who were recruited from the outpatient clinic of the Department of Vascular Surgery, Al-Hussein University Hospital. All patients were followed up monthly for 6 months. The duration of the study had been from 6 to 12 months from July 2018 to July 2019. Patients were divided into 2 groups: group I: In this group patients with varicose veins were treated stage down before surgery and control group: This was an age and sex matched group of patients with the first group. The clinical and hemodynamic assessments were carried on. Duplex ultrasound was done at the end of follow up period to detect the degree of improvement.
\end{abstract}

Results: Mean duration of varicose veins was $3.0 \pm 0.2$ with a range of (1.5-5) years. Varicose veins were distributed in leg in 50\% of group I and 70\% of group II. Median baseline anatomical extent of varicose veins was 5 and 6 in group I and II respectively with range of 4-9. As regard symptoms, aching was present in 5\% of cases, heaviness was in 5\%, itching in $10 \%$ of cases, cosmetic concerns was in $5 \%$, swelling in $0 \%$ of cases. Regarding post intervention complications, pain was present in $15 \%$ of cases, swelling in 5\%, bruising in $10 \%$ of cases, and discoloration in $0 \%$, and pigmentation in $10 \%$ of cases. As regard comparison of the two groups regarding the patient satisfaction score, $40 \%$ of cases were highly satisfied in group one, compared with $25 \%$ of cases of group II. There was a high significant improvement of anatomical extent of varicose veins over 6 months follow up period.

Conclusion: Sclerotherapy before surgical treatment provided symptomatic relief and significant improvements and patient satisfaction in patients diagnosed with uncomplicated varicose veins.

Keywords: Varicose Veins, Sclerotherapy, Chronic Venous Insufficiency, Endovascular Management.

\section{INTRODUCTION}

For many people, varicose veins and spider veins are simply a cosmetic concern. For other people, varicose veins can cause aching pain and discomfort.
Sometimes varicose veins lead to moreserious problems. Varicose veins may be a signal to higher risk of other circulatory problems. Treatment may involve selfcare measures or procedures by your 


\section{MOHAMMED AHMED ABD EL-TAWAB et al.,}

doctor to close or remove veins (Papadakis et al., 2019).

Lower limb varicose veins are a common disease that affects almost a quarter of the adult population. They affect women more frequently than men (Barandiaran et al., 2012). It has a point prevalence of $20-25 \%$ in women, and 10 $15 \%$ in men over the age of 15 years. The overall prevalence has been reported as 20-60\% (Kanwar et al., 2010).

Other reasons for the development of varicose veins are refluxes in other truncal veins, such as the small saphenous vein (SSV), the anterior or posterior thigh circumflex vein, the Giacomini vein, and perforating veins. Imaging studies are generally not necessary for the extremity with color Doppler US (CDUS) (Oguzkurt, 2011).

Duplex ultrasonography (DUS) has evolved to become the primary diagnostic tool used to evaluate patients with superficial venous insufficiency (SVI) (Khilnani, 2013).

Patients for whom discomfort is the main problem should be advised that wearing support hosiery which can provide good relief. Elevation of the legs may relieve symptoms. Advice about regular exercise sounds sensible, but is not supported by any evidence. For people who are obese weight loss may reduce symptoms and would make any intervention easier and safer (but losing a lot of weight may make varicose vein more visible (Papadakis et al., 2019).

Surgical or endovascular ablation of the GSV is indicated when incompetence at the sapheno-femoral junction is present. Surgical ablation in the form of stripping has been considered the "gold standard" against which the less invasive newly introduced endovenous ablation techniques are compared (Sarma, 2014).

Foam sclerotherapy (FST) offers a number of advantages over traditional, liquid sclerotherapy, and allows a skilled practitioner to treat veins of larger diameter, including saphenous trunks. The ease of use, low complication rate, and high rate of efficacy make foam sclerotherapy are important tools in the treatment of varicose veins and venous ulcerations (Gibson and Kabnick, 2016).

The aim of the present work was to evaluate the effect of staging down of the lower limb varicose veins by injection sclerotherapy before surgical treatment in comparison with the standard procedure.

\section{PATIENTS AND METHODS}

This was a prospective comparative clinical study conducted in Al-Azhar University Hospitals over a period of 6 months on 40 patients who presented with spider varicose veins. Their age ranged from 25 to 42 years. Patients were divided into 2 groups: Transplant group: Patients with varicose veins were treated stage down before surgery, and control group: Age and sex matched.

Inclusion criteria: Varicose veins with no previous open surgical or endovascular interventional options.

Exclusion criteria: Renal failure on hemodialysis and active overwhelming infection in the affected limb that threatens the patient's life.

Each sharing person underwent the following: 
A. History taking: Detailed history for all patients and past history of previous interventions either endovascular or open vascular.

\section{B. Clinical examination: Blood} pressure, pulse, cardiovascular, neurological and respiration assessment and clinical assessment of the patient, degree of varicose veins.

\section{Investigations: Laboratory} workup and Duplex study and CT angiography Cardiological assessment.

In group I, varicose veins were injected to decrease its size and volume before remove it surgically, group II injection was done postoperatively.

All patients were followed up monthly for 6 months. The clinical and hemodynamic assessments of limb perfusion were carried on. Duplex ultrasound was done at the end of follow up period to detect the degree of improvement.

Ethical Consideration: Study protocol had been submitted for approval by Institution Research Board (IRB) of Faculty of Medicine, Al-Azhar University. Informed verbal consent had been obtained from each participant sharing in the study.

\section{Statistical analysis:}

Recorded data were analyzed using the statistical package for social sciences, version 20.0 (SPSS Inc., Chicago, Illinois, USA). Quantitative data were expressed as mean \pm standard deviation (SD). Qualitative data were expressed as frequency and percentage.

\section{The following tests were done:}

- Independent-samples t-test of significance was used when comparing between two means.

- Chi-square $\left(\mathrm{x}^{2}\right)$ test of significance was used in order to compare proportions between two qualitative parameters.

- The confidence interval was set to $95 \%$ and the margin of error accepted was set to $5 \%$. The p-value was considered significant when $\mathrm{P}$-value $\leq 0.05$.

- The Mann-Whitney U test was used as a nonparametric test that allows two groups to be compared without making the assumption that values are normally distributed.

\section{RESULTS}

In group I, 9(45.0\%) patients were males and $11(55.0 \%)$ were females. In group II, $8(40 \%)$ of patients were males and $12(60 \%)$ were female. This distribution was non-statistically different. Mean age of patients in Group I was 31.5 \pm 6.8 with a range of 25-39 years compared with $32.6 \pm 5.3$ with range of (27-42) years in group II. This difference was not statistically significant this table shows that mean duration of varicose veins ranging between (1.5-5) years in all cases with Mean \pm SD of $3.0 \pm 0.2$ in group I compared to $2.6 \pm 0.8$ in group II. Baseline anatomical extent of varicose veins was 5 in group I and 6 in group II. Varicose veins in group I presented in $10(50 \%)$ legs and 10(50\%) thighs. Group II had 14(70\%) legs and 6(30\%) thighs. 
No statistical difference was found regarding this distribution (Table 1).

Table (1):

\begin{tabular}{|c|c|c|c|}
\hline $\begin{array}{ll}\text { Groups } & \text { Parameter } \\
\end{array}$ & $\begin{array}{c}\text { Group I } \\
\mathbf{N}=20\end{array}$ & $\begin{array}{c}\text { Group II } \\
\mathbf{N}=\mathbf{2 0}\end{array}$ & $\mathbf{P}$ \\
\hline $\begin{array}{l}\text { Gender** } \\
\text { Male } \\
\text { Female }\end{array}$ & $\begin{array}{l}9(45.0 \%) \\
11(55.0 \%)\end{array}$ & $\begin{array}{l}8(40 \%) \\
12(60 \%)\end{array}$ & $>0.05$ \\
\hline $\begin{array}{l}\text { Age }(y)(\text { Mean } \pm \text { SD }) * \\
\text { Range }\end{array}$ & $\begin{array}{c}31.5 \pm 6.8 \\
(25-39)\end{array}$ & $\begin{array}{c}32.6 \pm 5.3 \\
(27-42)\end{array}$ & $>0.05$ \\
\hline
\end{tabular}

Table (2):

\begin{tabular}{|l|c|c|c|}
\hline Duration (years) (Mean \pm SD) & 2 & $2.6 \pm 0.8$ & \\
\hline Site of varicose veins** & $3.0 \pm 0.2$ & & \\
Leg & $\begin{array}{r}10(50 \%) \\
10(50 \%)\end{array}$ & $\begin{array}{c}14(70 \%) \\
6(30 \%)\end{array}$ & $>0.05$ \\
Thigh & 5 & 6 & $>0.05$ \\
\hline Baseline anatomical extent $* * *$ & $(4-9)$ & $(5-9)$ & \\
Median & & & \\
Range &
\end{tabular}

The chart below showed the change of symptoms from preoperative time till three months after intervention in both groups. All symptoms improved significantly except swelling. This may be from non-commitment to elastic stoking and continuous long standing postoperatively.
Symptoms reported in patients after 6 months were cosmetic concerns in 1 and 0 patient in group I and Group II, respectively. Swelling was found in 5 patients of group II. Itching was found in 3 patients in group II compared to 10 patients in group I. Heaviness pain was found in 5 and 2 patients in group I and II

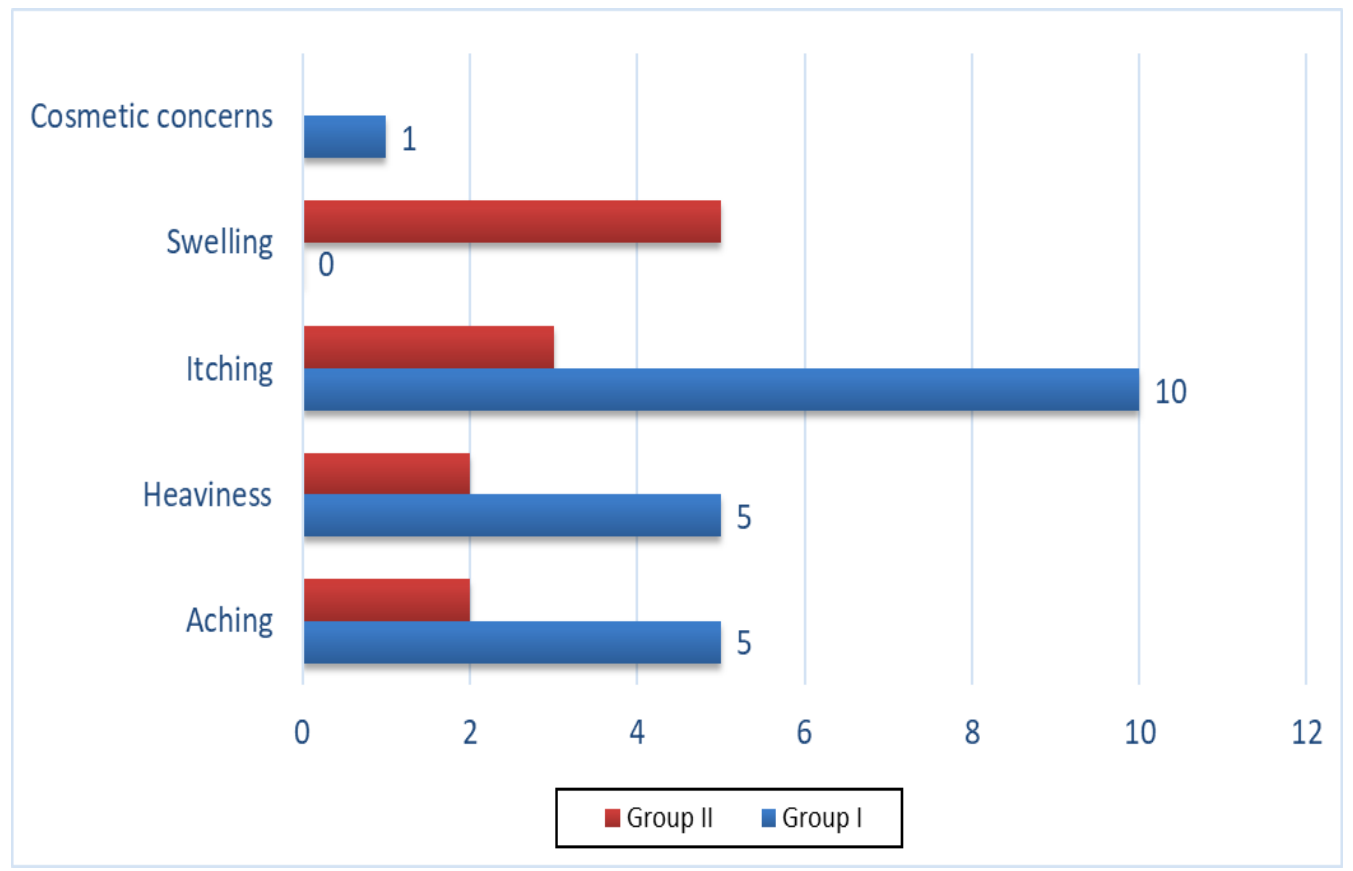

respectively. Also, aching was found in 5 
and 2 patients in group I and II respectively (Figure 1). Figure (1): Symptoms reported in patients after 6 months

Patients of group I had more This difference was statistically not satisfaction after 6 months of intervention. significant.

Table (3): Comparison of the two groups regarding the patient satisfaction score

\begin{tabular}{|l|c|c|c|}
\hline Groups & Group I & Group II & p \\
\hline Unsatisfied & $5(25.0 \%)$ & $4(20 \%)$ & \\
Somewhat satisfied & $7(35.0 \%)$ & $11(55 \%)$ & $>\mathbf{0 . 0 5}$ \\
Highly satisfied & $8(40.0 \%)$ & $5(25 \%)$ & \\
\hline
\end{tabular}

There is high significant improvement of anatomical extent of varicose veins over 6 months follow up period in both groups which was not statistically significant (Table 4).

Table (4): Overtime improvement in anatomical extent of varicose veins

\begin{tabular}{|c|c|c|c|c|c|c|}
\hline \multirow{2}{*}{$\begin{array}{l}\text { Anatomical } \\
\text { extent }\end{array}$} & \multicolumn{4}{|c|}{ Months post intervention } & \multirow[b]{2}{*}{$\mathbf{F}$} & \multirow[b]{2}{*}{$\mathbf{P}$} \\
\hline & Baseline & 1 & 2 & 3 & & \\
\hline Group I & 5 & 3 & 2 & 1 & \multirow{2}{*}{132.3} & \multirow{2}{*}{$<0.001$} \\
\hline Group II & 6 & 5 & 3 & 2 & & \\
\hline
\end{tabular}

$\mathrm{F}$ is for Freidman's test

The Rindfleisch-Friedel procedure of the early 1900s involved one incision to the level of the deep fascia that wrapped around the leg six times, creating a spiral gutter that brought into view a large number of superficial veins, each one of which was ligated.

Table (5) and Figures (2, 3) showed that there was a significant positive correlation after 6 months. Anatomical extent of varicose veins and duration of varicose veins $(\mathrm{p}=0.048)$, and baseline anatomical extent of varicose veins $(\mathrm{p}=0.002)$, while there was no significant correlation between 6 months anatomical extent of varicose veins and age, gender or site of varicose veins $(p>0.05)$.

Spearman correlation: it evaluates the linear association between 2 quantitative variables (one is the independent var. $\mathrm{X}$, and the other is the dependent var., Y). Value of "r" ranges from -1 to 1 .

Table (5): Correlations between anatomical extent of varicose veins after 6 month and different parameters

\begin{tabular}{|l|c|c|}
\hline \multicolumn{3}{|c|}{ 6 months anatomical extent of varicose veins (in all cases) } \\
\hline Sex & r & P value \\
\hline Age & 0.213 & 0.165 \\
\hline Duration of varicose veins & 0.124 & 0.432 \\
\hline Site of varicose veins & 0.433 & $\mathbf{0 . 0 4 8}$ \\
\hline Baseline Anatomical extent of varicose veins & 0.144 & 0.761 \\
\hline
\end{tabular}

$r$ is for spearman's correlation . $\mathrm{p}$ value is significant if $<0.05$ 


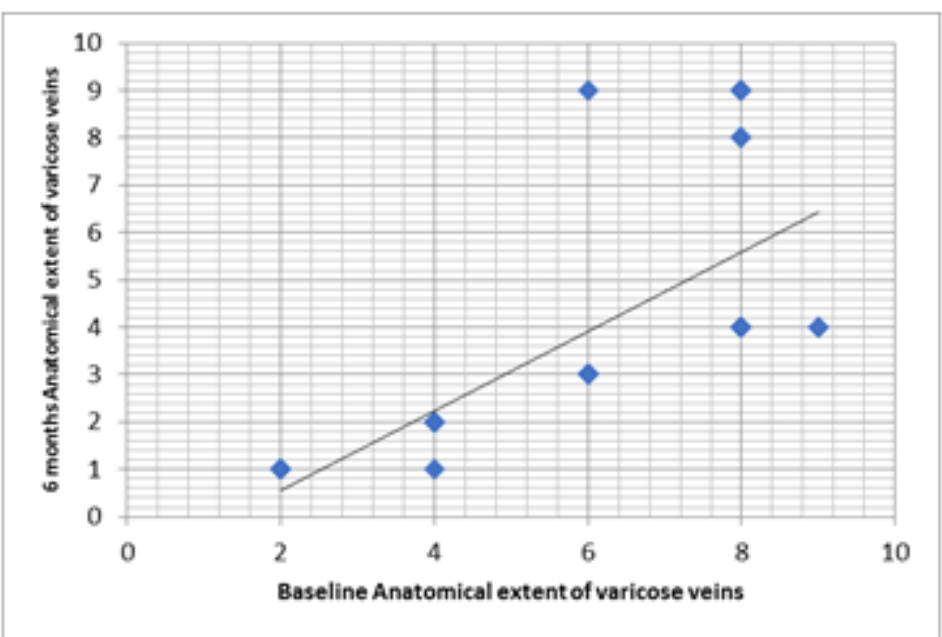

Figure (2): Correlation between baseline anatomical extent of varicose veins and 6 month anatomical extent of varicose veins.

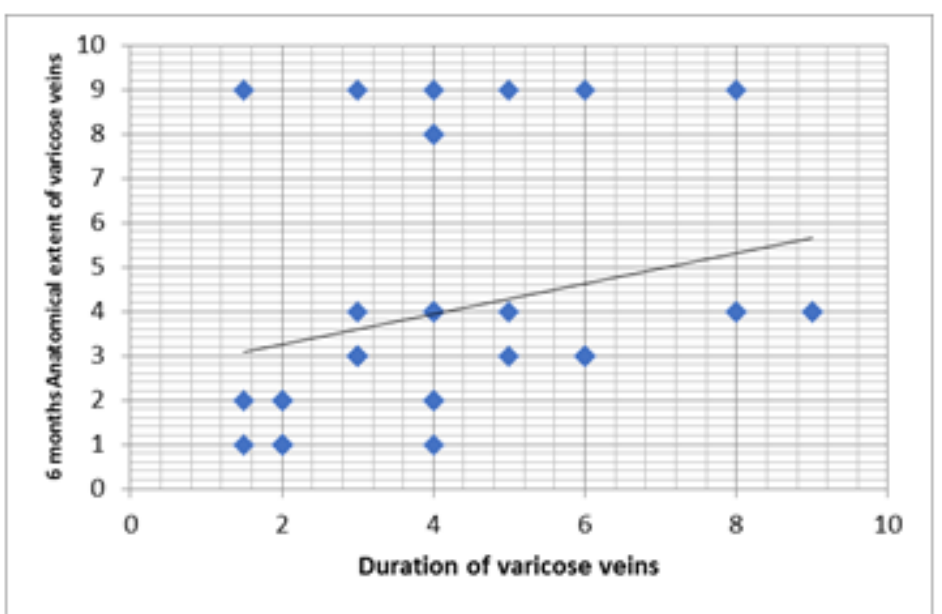

Figure (3): Correlation between duration of varicose veins and 6 month anatomical extent of varicose veins

All symptoms improved significantly except swelling. This may be from noncommitment to elastic stoking and continuous long standing postoperatively (Table 6).

Table (6): Overtime improvement of symptoms of varicose veins

\begin{tabular}{|l|c|c|c|c|c|}
\hline \multicolumn{1}{|c|}{ Groups } & \multicolumn{2}{|c|}{ Group I } & \multicolumn{2}{c|}{ Group II } & \multirow{2}{*}{ P } \\
\cline { 1 - 5 } Parameters & Pre & 6 months & Pre & 6 months & \\
\hline Aching & 5 & 3 & 4 & 2 & $<\mathbf{0 . 0 5}$ \\
\hline Heaviness & 5 & 2 & 6 & 3 & $<\mathbf{0 . 0 5}$ \\
\hline Itching & 10 & 3 & 11 & 4 & $<\mathbf{0 . 0 5}$ \\
\hline Swelling & 0 & 2 & 1 & 2 & $>0.05$ \\
\hline Cosmetic concerns & 9 & 4 & 8 & 3 & $<\mathbf{0 . 0 5}$ \\
\hline
\end{tabular}


Mcnemar test was used to find the change in proportion for the paired data between group 1 and group 2 .

Regarding post intervention complications, the present study showed

\section{DISCUSSION}

The usual plan of care of varicose veins is phlebectomy then sclerotherapy of residual varices. This study suggested down staging of varicose veins by sclerotherapy before surgical intervention.

The study was a prospective clinical trial study design included 40 patients were evaluated for surgical needling or injection as detected by history and examination as basic criteria of diagnosis. The duration of the study had been from 6 to 12 months.

Their ages ranged between 25-42 years, consecutively recruited from the outpatient clinic of the Department of Vascular Surgery, Al-Hussein University Hospital. Cases were divided into two groups matched in age and gender. This age range was similar to Chen et al. (2011), who conducted a randomized clinical trial for uncomplicated varicose veins with mean age of 49.5 versus 52.6 years and women 69.8 versus 42.0 .

In the present study in our hands, mean duration of varicose veins was $3.0 \pm 0.2$ with a range of 1.5-5 years. Half of the patients had primary varicose veins, and the other half had secondary varicose veins. Varicose veins were distributed in leg in $50 \%$ of group I and $70 \%$ of group II. Median baseline anatomical extent of varicose veins was 5 and 6 in group I and II respectively with a range of 4-9. that pain was present in $15 \%$ of cases, swelling in $5 \%$, bruising in $10 \%$ of cases, discoloration in $0 \%$, and pigmentation in $10 \%$ of cases.

Lower limb symptoms such as heaviness or tension, aching, a feeling of swelling, restless legs, cramps, itching, and tingling were attributed to varicose veins. Patients are more likely to have symptoms and increasing severity of symptoms with increasing CEAP clinical class (C0 to C6) (Raetz et al., 2019).

As regard symptoms, the present study showed that aching was present in $5 \%$ of cases, heaviness was in $5 \%$, itching in $10 \%$ of cases, cosmetic concerns was in $5 \%$, and swelling in $0 \%$ of cases.

Our results are supported by findings of Chen et al. (2011) as they reported that 1 year after operation patients reported that 80 per cent (for aching) to 90 per cent (for swelling) of their symptoms were absent or better than before surgery, compared with 23 per cent (for aching) to 68 per cent (for swelling) among those treated conservatively. Indeed, 22 per cent of the latter reported that they no longer had cosmetic concerns. These observations suggest a substantial benefit from surgery but perhaps support the case for careful evaluation of patients' symptoms and problems when considering surgical treatment.

Surgical or endovascular ablation of the GSV is indicated when incompetence at the sapheno-femoral junction is present. Surgical ablation in the form of stripping has been considered the "gold standard" against which the less invasive newly 


\section{MOHAMMED AHMED ABD EL-TAWAB et al.,}

introduced endo venous ablation techniques are now compared (Sarma, 2014).

Foam sclerotherapy (FST) offers a number of advantages over traditional liquid sclerotherapy, and allows a skilled practitioner to treat veins of larger diameter, including saphenous trunks. The ease of use, low complication rate, and high rate of efficacy make foam sclerotherapy an important tool in the treatment of varicose veins and venous ulcerations (Gibson and Kabnick, 2016).

Regarding post intervention complications, the present study showed that pain was present in $15 \%$ of cases, swelling in $5 \%$, bruising in $10 \%$ of cases, discoloration in $0 \%$, and pigmentation in $10 \%$ of cases.

Rasmussen et al. (2011) conducted study about comparing end of venous laser ablation, radiofrequency ablation, foam sclerotherapy and surgical stripping for great saphenous varicose veins and reported that Complications were mostly minor. Only two events were classified as major complications. One patient had an iliac vein thrombosis and pulmonary embolus within 1 week of UGFS ultrasound-guided foam sclerotherapy. The patient was subsequently treated with catheter-directed thrombolysis. The other had thrombosis of the popliteal vein within the first month after stripping. Significantly more patients in the RFA (radiofrequency ablation) and foam groups developed post intervention superficial phlebitis. It was not recorded specifically whether the phlebitis was related to the GSV (great saphenous vein) or the tributaries (Rasmussen et al., 2011).
Nootheti et al. (2010) conducted study about efficacy of graduated compression stockings for an additional 3 weeks after sclerotherapy treatment of reticular and telangiectatic leg veins and reported that $45 \%$ and $5 \%$ of the 4 -week compression group reported the presence of swelling and bruising, respectively, compared with the 1-week compression group, who developed swelling in $25 \%$ and bruising in $15 \%$.

Measurement of the extent of the varicose veins was based on an anatomical classification developed at the start of this trial and published previously (Papadakis et al., 2019).

Clear expectations about the likely outcomes of treatment are important for patients' satisfaction (Gandhi et al., 2010).

As regard Comparison of the two groups regarding the patient satisfaction score, the present study shows that $40 \%$ of cases were highly satisfied in group one, compared with $25 \%$ of cases of group II. As regard Overtime improvement in Anatomical extent of varicose veins, there is high significant improvement of Anatomical extent of varicose veins over 6 months follow up period.

Our results are supported by findings of Chen et al. (2011) as they reported that there was no significant change in the conservative group, whereas 70 per cent of those in the surgical group had no varicose veins on clinical assessment at 1 year $(\mathrm{P}<0 \bullet 010, \chi 2$ test for trend). In addition to improving specific symptoms, surgical treatment was associated with more improvement in physical and social functioning, energy/vitality and general 
health at 1 year than conservative measures.

Nootheti et al. (2010) reported that patients who wore the Class I graduated stockings for an additional 3 weeks reported feelings of leg comfort while wearing the stockings during full motion and at rest.

In the study in our hands there is significant positive correlation between 6 month anatomical extent of varicose veins and duration of varicose veins and baseline anatomical extent of varicose veins while there is no significant correlation between 6 month Anatomical extent of varicose veins and age, gender or site of varicose veins.

This study has shown clear advantages for sclerotherapy before surgical treatment of varicose veins across a whole range of outcome measures relating to health status, quality of life and patient satisfaction.

\section{CONCLUSION}

Sclerotherapy before surgical treatment provides symptomatic relief and significant improvements and patient satisfaction in patients diagnosed with uncomplicated varicose veins.

\section{REFERENCES}

1. Barandiaran J, Hall T, El-Barghouti $\mathrm{N}$ and Perry E. (2012): Day Case Management of Varicose Veins. Vasc Surg Prin Pract., 14: 7390.

2. Chen CY, Hsieh TC and Huang YK (2011): Retrospective comparison of clinical outcomes between endovenous laser and saphenous veinsparing surgery for treatment of varicose veins. World Journal of Surgery, 35(7): 1679-1686.

3. Gandhi A, Froghi F, Shepherd AC, Shalhoub J, Lim CS, Gohel MS and Davies AH. (2010): A Study of Patient Satisfaction
Following Endothermal Ablation for Varicose Veins. Vasc Endovascular Surg., 44(4):274-8.

4. Gibson $K$ and Kabnick L. (2016): A multicenter, randomized, placebo-controlled study to evaluate the efficacy and safety of Varithena ${ }^{\circledR} \quad$ (polidocanol endovenous microfoam $1 \%$ ) for symptomatic, visible varicose veins with saphenofemoral junction incompetence. Phlebology: The Journal of Venous Disease, 32(3): 185-193.

5. Kanwar A, Hansrani M, Lees $T$ and Stansby G. (2010): Trends in varicose vein therapy in England: radical changes in the last decade. Annals of the Royal College of Surgeons of England, 92(4): 341-346.

6. Khilnani NM. (2013): Venous Duplex Ultrasound in Patients with Chronic Venous Disorders. BMJ, 3: 33-44.

7. Nootheti PK, Cadag KM, Magpantay A and Goldman MP. (2010): Efficacy of Graduated Compression Stockings for an Additional 3 Weeks after Sclerotherapy Treatment of Reticular and Telangiectatic Leg Veins. Dermatologic Surgery, 35(1): 53-58.

8. Oguzkurt L. (2011): Endovenous laser ablation for the treatment of varicose veins. Diagnostic and Interventional Radiology, 18(4):417-22.

9. Papadakis MA, McPhee SJ and Rabow MW. (2019): Blood vessel and lymphatic disorders. In: Current Medical Diagnosis \& Treatment. 58th ed. Pbl. New York, N.Y. The McGraw-Hill Companies, P. 319.

10. Raetz J, Wilson $M$ and Collins K. (2019): Varicose veins: Diagnosis and treatment. American Family Physician, 99(11), 682-688.

11. Rasmussen LH, Lawaetz $M$, Bjoern $L$, Vennits B, Blemings A and Eklof B. (2011): Randomized clinical trial comparing endovenous laser ablation, radiofrequency ablation, foam sclerotherapy and surgical stripping for great saphenous varicose veins. British Journal of Surgery, 98(8): 1079-1087.

12. Sarma N. (2014): Guidelines and recommendation on surgery for venous incompetence and leg ulcer. Indian Dermatol Online J., 5(3): 390-395. 


\section{مرحلة ما قبل الجر احة في الدو الي الوريدية}

محمد أحمد أحمد عبد التواب, إسحاق عبد العال عبد العلي, محمد يحيى زكرياث قسمي الجراحة العامة و جراحة الأوعية الاموية*ث، كلية الطب، جامعة الازهر

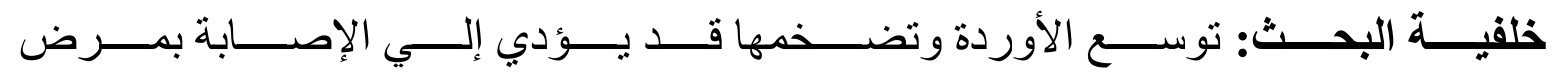

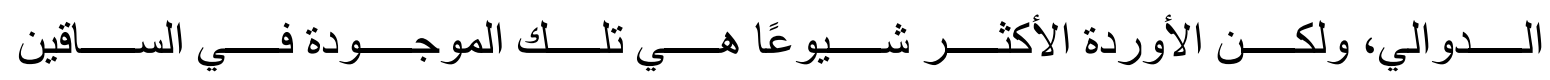

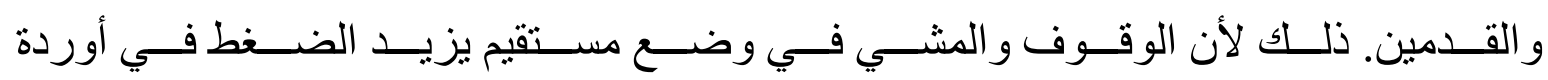

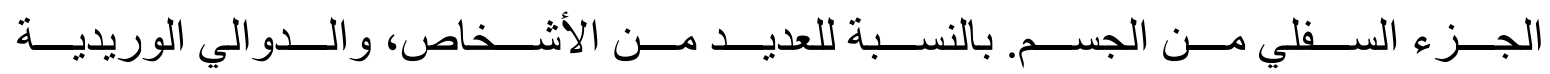



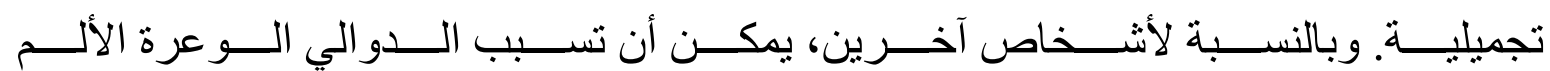
وفي بعض الأحيان تؤدي الدو الي إلى مشاكل أكثر خطورة.

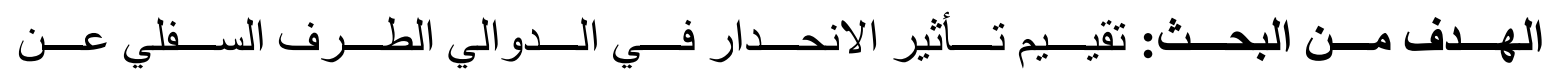
طريق الحقن المصلب قبل العلاج الجراحي بالمقارنة مع الإجر اء القياسي.

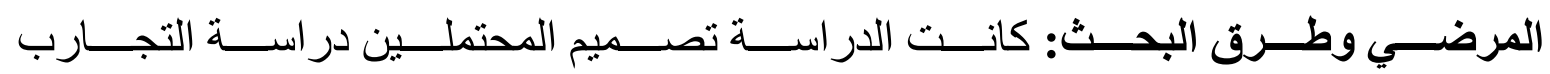

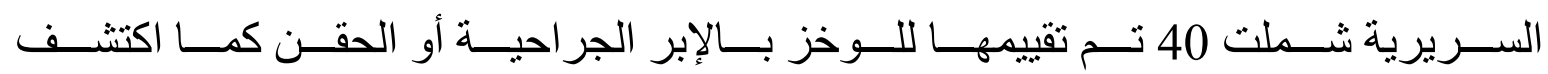

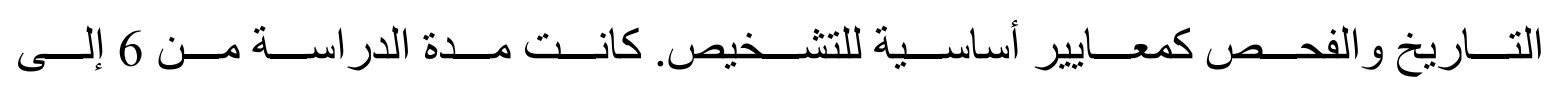

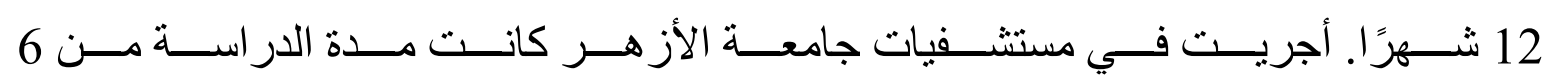

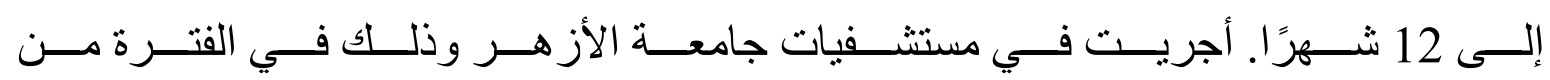
شهر يوليو 2018 وحتى يوليو 2019.

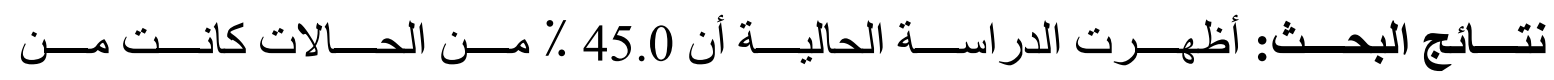

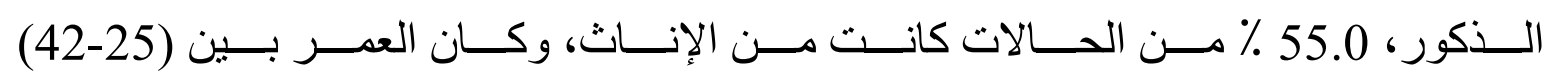





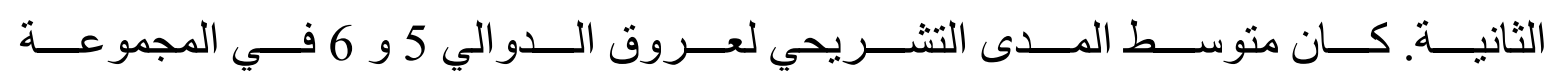

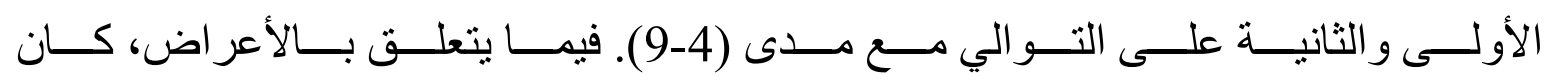






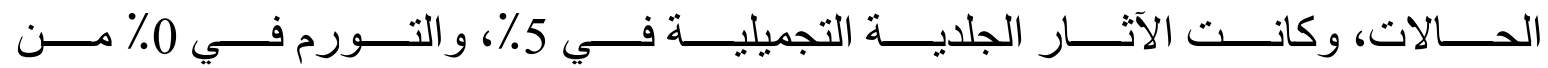

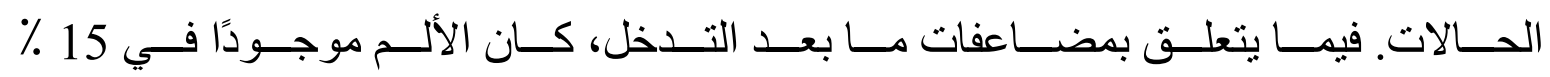



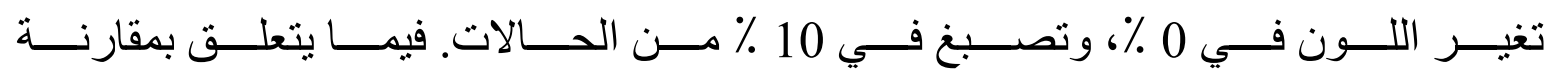

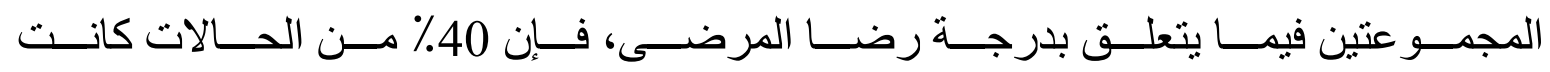



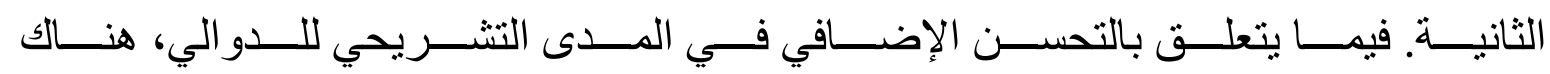


المتابعة.

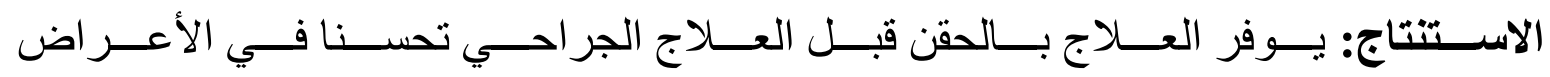

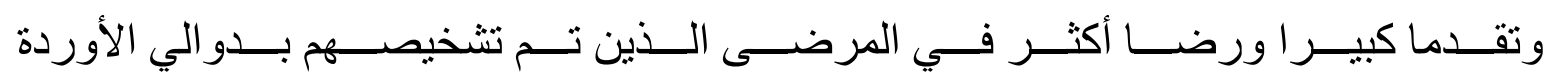
غير المعقدة. 